\title{
Profile of Children Admitted for Severe Acute Malnutrition in a Tertiary Hospital in Southwestern Nigeria
}

\section{Adefunke Olarinre Babatola ${ }^{1}$, Oladele Simeon Olatunya ${ }^{1}$, Temitope Olumuyiwa Ojo $^{2}$, Adekunle Bamidele Taiwo ${ }^{1}$, Joseph Olusesan Fadare ${ }^{3}$}

${ }^{1}$ Department of Paediatrics, Ekiti State University/ Ekiti State University Teaching Hospital, Ado-Ekiti, Ekiti State, Nigeria

${ }^{2}$ Department of Community Medicine, Obafemi Awolowo University, Ile-Ife, Osun State, Nigeria

${ }^{3}$ Department of Medicine, Ekiti State University/ Ekiti State University Teaching Hospital, Ado-Ekiti, Ekiti

State, Nigeria

\author{
Correspondence: \\ Adefunke Olarinre Babatola \\ Department of Paediatrics \\ Ekiti State University Teaching Hospital, \\ PMB 5353, Ado-Ekiti, Ekiti State, \\ Nigeria. \\ Telephone: +2348035682315 \\ Email: mamafunky@yahoo.co.uk
}

DOI:10.3126/jnps.v39i1.21604

Submitted on: 2018-11-07

Accepted on: 2020-03-24

Acknowledgements: We thank $\mathrm{Mr}$. Mustapha of the department of health information, Ekiti State University Teaching Hospital, Ado-Ekiti for his assistance in data collection.

Funding: Nil

Conflict of Interest: None declared

Permission form IRB: Yes

To cite this article: Babatola $\mathrm{AO}$, Olatunya OS, Ojo TO, Taiwo AB, Fadare JO. Profile of children admitted for severe acute malnutrition in a tertiary hospital in Southwestern Nigeria. J Nepal Paediatr Soc. 2019;39(1):42-8.

\section{ABSTRACT}

Introduction: This study assessed the socio-demographic profile, outcomes of treatment and challenges encountered in the management of children admitted for Severe Acute Malnutrition at the Paediatric Unit of a State University Teaching Hospital, Ado-Ekiti, Nigeria.

Methods: A retrospective cross-sectional study was conducted. The records of twenty-five children with SAM admitted from March 2013March 2018 were reviewed. SAM was defined according to the Wellcome Classification based on child's weight and oedema status. Data on demographic characteristics, presenting symptoms, co-morbid conditions, duration of admission and outcome were extracted.

Results: There were $13(52.0 \%)$ males and 12 (48.0\%) females. The median age of children with SAM was eight months. Eighteen children $(72 \%)$ were marasmic, four $(16 \%)$ had kwashiorkor while three $(12 \%)$ had marasmic-kwashiorkor. Common presenting symptoms included poor weight gain (59.1\%), fever $(54.5 \%)$ and diarrhoea $(36.4 \%)$. Majority $(84.0 \%)$ of the patients had co-morbid conditions which included sepsis $(66.7 \%)$, anaemia $(37.5 \%)$, hypoglycaemia $(16.7 \%)$ and hypothermia $(16.7 \%)$. Twenty-one $(84.0 \%)$ children were fully vaccinated for age, two $(8.0 \%)$ had partial vaccination while two $(8.0 \%)$ were never vaccinated. Only two $(8.0 \%)$ had exclusive breastfeeding, 19 $(76.0 \%)$ had mixed feeding from birth. Majority $(60 \%)$ of the children had one or more social challenges such as teenage parents and financial constraints. Mean duration of admission was 4.56 days. Twelve (48.0\%) left against medical advice, nine (36.0\%) were discharged, one $(4.0 \%)$ was referred to another tertiary facility and three (12.0\%) deaths were recorded.

Conclusions: Many of the children admitted for SAM in our study had social problems and almost half of them left the hospital against medical advice. Besides health problem, social factors may play more role in SAM.

Key words: Kwashiorkor; Marasmus; Marasmic-kwashiorkor; outcome 


\section{INTRODUCTION}

Malnutrition in childhood remains a serious public health challenge and its impact is devastating. Globally in 2017, the World Health Organisation reported that 151 million children aged under five years were stunted, 51 million wasted and 16 million severely wasted. ${ }^{1}$ Nigeria has a fair share of this dismal statistics: the country has the highest number of stunted children under age five in subSaharan Africa and second highest in the world with more than 10 million stunted children. ${ }^{2}$ An estimated 2.5 million children under the age of five suffer from severe acute malnutrition in Nigeria annually. ${ }^{3}$ There is no state in Nigeria without children with severe acute malnutrition (SAM) though the problem is more prevalent in the northern part of the country. ${ }^{3}$

SAM ends many lives directly and makes children nine times more likely to die from common childhood illnesses. ${ }^{3}$ Although malnutrition is largely preventable, the causes are complex ranging from lack of food to political issues. ${ }^{4}$ Children suffering from SAM need immediate medical treatment and long-term management and followup. A Community based management of acute malnutrition (CMAM) programme was introduced in Nigeria in 2009. This programme is operational in 11 northern states in Nigeria and it is largely supported by non- governmental organisations and international partners. ${ }^{5}$ With this approach, children with severe acute malnutrition without medical complications and those who have had their infections treated in the hospital facility are managed on out-patient basis. ${ }^{3}$ UNICEF has reported that over two million Nigerian children have been treated since the programme was introduced, with the cure rate of about $85 \% .^{5}$ Recently, in 2016, the Federal Ministry of Health produced a guideline on the inpatient management of severe acute malnutrition for infants and young children in Nigeria. In this document, it is recommended that after the initial management of emergency conditions in children with SAM, they should be managed on outpatient basis. ${ }^{6}$ To ensure better preparation for the adoption of the National guideline in our tertiary facility and advocating for the adoption of CMAM in Ekiti State generally, it is important to review the profile of SAM cases managed in the past five years in the facility. This study assessed the socio-demographic profile, outcomes of treatment and challenges encountered in the management of children admitted for SAM in a tertiary hospital in southwestern, Nigeria.

\section{METHODS}

A cross-sectional descriptive study was carried out to assess the socio-demographic profile, outcomes of treatment and challenges encountered in the management of children admitted for SAM at Children Emergency Ward (CEW) of a State University Teaching Hospital in Ado-Ekiti, Nigeria. The case notes of all patients admitted for SAM at the Children Emergency Ward from March 2013March 2018 were retrieved and a checklist was used to extract information from the patients' case files. The information was categorised into sociodemographic characteristics, presenting symptoms, co-morbid conditions, duration of admission and clinical outcomes. SAM was defined according to the Wellcome Classification ${ }^{7}$ based on child's weight and oedema status.

Data analysis was performed using the IBM/ Statistical Package for Social Sciences (SPSS) version 20.0. Results are presented as tables and charts. Frequencies and percentages were used to estimate proportions for categorical variables while continuous variables were summarised using median and range as well as mean and standard deviation as appropriate. A p-value $<0.05$ was regarded as statistically significant. An ethical clearance certificate was obtained from University Ethics and Research Committee before commencement of the study.

\section{RESULTS}

The medical records of 25 children with severe acute malnutrition (SAM) were reviewed. There were $13(52.0 \%)$ males and $12(48.0 \%)$ females. The median age of the children was eight months (interquartile range 4 to 12 months). Seventeen $(68 \%)$ of them reside in urban area while the rest eight $(32 \%)$ in the rural area.

Clinical profile of the study population: The mean weight of the children at admission was $4.27 \pm$ $1.47 \mathrm{~kg}$. Marasmus was the predominant clinical 


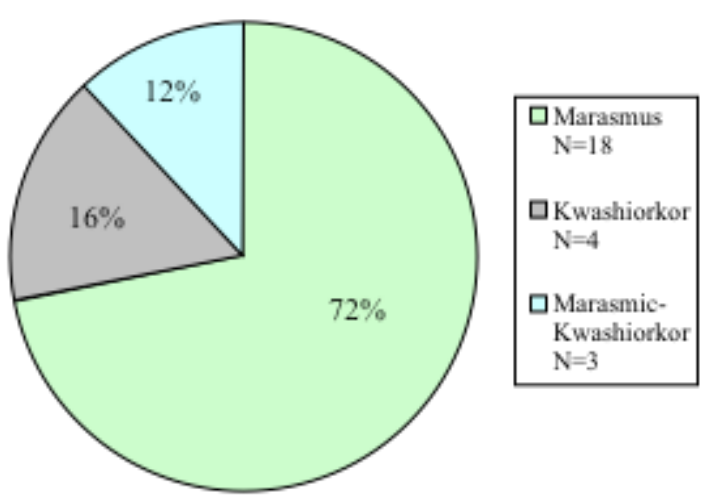

Figure 1. Distribution of clinical forms of SAM

form of severe acute malnutrition. Figure 1 shows the distribution of the clinical forms of severe acute malnutrition. The common presenting symptoms of the children with severe acute malnutrition included poor weight gain (59.1\%), fever (54.5\%) and diarrhoea (36.4\%) Table 1. Majority (84.0\%) of the patients had co-morbid conditions which included sepsis $(66.7 \%)$, anaemia $(37.5 \%)$, hypoglycemia $(16.7 \%)$ and hypothermia $(16.7 \%)$. Of the 18 children with documented Human immunodeficiency virus (HIV) screening test results, 2 (11.1\%) tested positive and $16(88.8 \%)$ tested negative. However, the two positive HIV patients were cases of Marasmus. Table II shows the distribution of the co-morbid conditions present in the malnourished children.

Majority $(60 \%)$ of the children had one or more social challenges such as teenage parents, grandparents as sole caregivers and financial constraints. Table III shows the distribution of associated challenges faced by the children with malnutrition.

Twenty-one (84.0\%) children were fully vaccinated for age, two $(8.0 \%)$ had partial vaccination while two $(8.0 \%)$ were never vaccinated. With regards to breastfeeding, only two $(8.0 \%)$ of the malnourished children were exclusively breastfed. Also, only two $(8.0 \%)$ of them were not exposed to breastfeeding at all. The remaining $21(84.0 \%)$ had mixed feeding from birth.

The range of duration of admission was one to 17 days, median was three days (interquartile range 1.0-6.5 days). Forty-eight percent of the
Table 1. Signs and symptoms at admission

\begin{tabular}{|l|r|r|}
\hline Signs and symptoms & $\begin{array}{l}\text { Number of } \\
\text { cases }\end{array}$ & $\begin{array}{l}\text { Percentage } \\
(\%)\end{array}$ \\
\hline Poor weight gain & 13 & 59.1 \\
\hline Fever & 12 & 54.5 \\
\hline Diarrhoea & 8 & 36.4 \\
\hline Bilateral leg swelling & 7 & 31.8 \\
\hline Pallor & 5 & 22.7 \\
\hline Cough & 5 & 22.7 \\
\hline Weight loss & 4 & 18.2 \\
\hline Difficulty with breathing & 3 & 13.6 \\
\hline Rash & 3 & 13.6 \\
\hline Seizures & 1 & 4.5 \\
\hline Unconsciousness & 1 & 4.5 \\
\hline
\end{tabular}

malnourished children left against medical advice (LAMA). Table 4 shows the distribution of outcome of admission.

\section{DISCUSSION}

SAM continues to be an important contributor to childhood morbidity and mortality globally with more impact in developing countries such as Nigeria. There have been mixed reports on gender distribution of SAM. ${ }^{8-19}$ While some authors have found male preponderance, ${ }^{10-16}$ others have documented having more females involved with SAM in their works. ${ }^{17-19}$ Although there was a slight male preponderance (52\% vs $48 \%$ ) with regards to involvement with SAM among our study population, this did not attain statistical significance. Our study finding is therefore similar to two previous reports in India ${ }^{8,9}$ where there was no sex predilection with regards to SAM.

The median age of the children in our study was eight months with the age range of three to 24 months. This finding is similar to that of Chiabi et al. ${ }^{11}$ in Cameroon but lower than the median ages of 17 months and 24 months reported by Irena et al. ${ }^{14}$ in Zambia and Kabalo et al. ${ }^{20}$ in Southern Ethiopia respectively. This could be because the Zambian and Ethiopian studies involved children 
Table 2. Distribution of co-morbid conditions

\begin{tabular}{|l|r|r|}
\hline $\begin{array}{l}\text { Co morbid } \\
\text { condition }\end{array}$ & $\begin{array}{l}\text { Number of } \\
\text { cases } \mathbf{( N = 2 4 )}\end{array}$ & $\begin{array}{l}\text { Percentage } \\
(\%)\end{array}$ \\
\hline Sepsis & 16 & 66.7 \\
\hline Anaemia & 9 & 37.5 \\
\hline Hypothermia & 4 & 16.7 \\
\hline Dehydration & 4 & 16.7 \\
\hline Hypoglycemia & 4 & 16.7 \\
\hline Candidiasis & 4 & 16.7 \\
\hline Diarrhoea & 3 & 12.5 \\
\hline Stomatitis & 2 & 8.3 \\
\hline Malaria & 1 & 4.2 \\
\hline $\begin{array}{l}\text { Disseminated } \\
\text { tuberculosis }\end{array}$ & 1 & 4.2 \\
\hline
\end{tabular}

from six months while our study involved children from one month upward.

The most predominant clinical form of malnutrition in our study was marasmus (72\%) followed by kwashiorkor (16\%). Several works have made the same observation ${ }^{11,12,20,21}$ However, this finding is at variance with the findings of Gabbad et al. ${ }^{22}$ in Sudan and Misganaw et al. ${ }^{23}$ in Ethiopia who found kwashiorkor to be the most predominant clinical form in their study. The higher preponderance of marasmus in our study is not clear to us. However, this may be due to higher rates of exposure to inadequate breastfeeding (two cases of total absence of breastfeeding and 21 cases of mixed feeding) 23 (92.0\%) among our study participants, as marasmus tend to present earlier than kwashiorkor given that breastmilk is supposed to be the major source of nutrition for young infants.

Table 4. Distribution of outcome of admission

\begin{tabular}{|l|r|r|}
\hline Outcome & Number $\mathbf{N}=\mathbf{2 5}$ & Percentage (\%) \\
\hline LAMA & 12 & 48.0 \\
\hline Discharged & 9 & 36.0 \\
\hline Referred & 1 & 4.0 \\
\hline Death & 3 & 12.0 \\
\hline
\end{tabular}

Table 3. Mean distribution of platelet count according to birth weight of neonates

\begin{tabular}{|l|r|r|}
\hline Challenges & $\begin{array}{l}\text { Number of } \\
\text { children } \\
(\mathbf{N = 2 5 )}\end{array}$ & \multicolumn{2}{|c|}{$\begin{array}{l}\text { Percentage } \\
\text { (\%) }\end{array}$} \\
\hline $\begin{array}{l}\text { Residing with } \\
\text { grandparents }\end{array}$ & 5 & 20.0 \\
\hline Child being a twin & 4 & 16.0 \\
\hline Mother is deceased & 4 & 16.0 \\
\hline Financial constraints & 2 & 8.0 \\
\hline Dysfunctional home & 2 & 8.0 \\
\hline Teenage parent & 1 & 4.0 \\
\hline $\begin{array}{l}\text { Large family } \\
\text { (six children) }\end{array}$ & 1 & 4.0 \\
\hline
\end{tabular}

Also, the observation that kwashiorkor is the second most common form of malnutrition in this study conforms with the high rates of these two conditions in the developing countries. ${ }^{20}$ However, that none of the kwashiorkor cases was associated with HIV infection further attests to earlier observation that HIV infection is not commonly associated with kwashiorkor in children with $\mathrm{SAM}^{24}$

The common presenting symptoms found in our study included poor weight gain (59.1\%), fever $(54.5 \%)$ and diarrhoea (36.4\%). Chiabi et al. ${ }^{11}$ in Cameroon and Choudhary et al. ${ }^{13}$ in India reported similar findings of weight loss and fever as the main symptoms of their study participants at admission. Baruah et al. ${ }^{18}$ in India also reported that fever was the most common presenting complaints amongst malnourished children in their study. The high fever rate among children with SAM may not be unconnected with their expected poor immunity with attendant opportunistic infections.

The most common co-morbid condition found in our study was sepsis $(66.7 \%)$ followed by anaemia $(37.5 \%)$, with malaria found in only one $(4.2 \%)$ case. Similar to our findings, two previous studies from Cameroon ${ }^{11}$ and Karnataka ${ }^{8}$ also reported that sepsis was one of the most common co-morbid conditions found amongst malnourished children. Similarly, Barauh et al. ${ }^{18}$ in India reported that 
urinary tract infection was the commonest comorbid condition in their study. Diarrhoea, malaria, sepsis and severe anaemia were the prevalent malnutrition related co morbid conditions reported by Ubesie et al. ${ }^{21}$ in Enugu, Nigeria. Misganaw et al. ${ }^{23}$ in Ethiopia also reported that diarrhoea, tuberculosis and pneumonia were the most commonly encountered co morbid conditions in their study. However, and on the contrary, Malaria which accounted for only $4.2 \%$ of the co-morbid conditions in our study was reported by Walana and colleagues $^{10}$ in Ghana to be the most common in their study representing $28.1 \%$ of co-morbidities in their study. This observed disparity in their findings compared to this study may be due to regional differences and larger size of their study. That a large proportion $(84.0 \%)$ of our study participants had associated co-morbid conditions is also not surprising and is in keeping with previous findings by other authors. ${ }^{8,11,21}$ However, Kabalo et al..$^{22}$ in Ethiopia reported a lower prevalence of comorbidity (31.7\%) in their study.

In our study, majority (84.0\%) of the children were fully vaccinated for age and this is similar to the results of studies by Dhanalaskshmi et al. ${ }^{8}$ in India and Misganaw et al. ${ }^{23}$ in Ethiopia. However, it is at variance with the report of Das et al. ${ }^{17}$ in India who found that majority of the malnourished children in their study were partly immunised (85.7\%). It was observed that majority of our study participants were fully vaccinated and this probably reflected the generally high level of immunisation coverage in the community. The poor breastfeeding status of patients with SAM as found in this study is in keeping with previous reports. Dhanalaskshmi et al. ${ }^{8}$ in India reported that $91 \%$ of their SAM patients who were less six months of age had mixed feeding. Similarly, Ubesie et al..$^{21}$ in Enugu, Nigeria reported that only about $18 \%$ of their study participants had exclusive breastfeeding. Also, Das et al. ${ }^{17}$ in India reported that only $10 \%$ of the children studied had exclusive breastfeeding. The findings of a high prevalence of mixed feeding and low exclusive breastfeeding rate amongst malnourished children underscore the importance of breastfeeding in the optimal nutrition of children.
In our study, the median duration of admission of our patients was three days. This is slightly lower than median duration of hospitalisation of seven days reported by Nhampossa et al. ${ }^{25}$ in southern Mozambique and lower than 18 days and 44.5 days reported by Burrell et al ${ }^{26}$ in Gambia and Ndzo et al. ${ }^{27}$ in Cameroon respectively. The short durations of admission observed in our study may be explained by the fact that most of our patients left the hospital against medical advice (LAMA). Eze et al. ${ }^{28}$ in Enugu, Nigeria have reported that leaving against medical advice is associated with short admission period. We observed in our study that about $50 \%$ of patients left against medical advice (LAMA), while only $36 \%$ were discharged.

The observed higher rates of LAMA in this study relative to others, ${ }^{10-12,20,22}$ may stem from the fact that many of them $(60 \%)$ had some forms of social challenges such as teenage parents, grandparents as sole caregivers and financial constraints. Therefore, it could be speculated that most of our patients that LAMA probably left before they were fit for discharge because of economic or social reasons. Eze et al. ${ }^{28}$ in Enugu, Nigeria and Fadare ${ }^{29}$ et al. in Ido-Ekiti, both in Nigeria found that financial constraints was one of the main reasons why patient discharge themselves against medical advice.

The $12.0 \%$ mortality rate among patients with SAM in this study is in agreement with mortality rates reported for SAM by some earlier authors ${ }^{10,11,17}$ However, Ali et al. ${ }^{9}$, Kabalo et al. ${ }^{20}$ and Misganaw et al. ${ }^{23}$ reported lower mortality rates of $2.8 \%, 1.2 \%$, and $5.8 \%$ in their respective studies. On the contrary, a higher mortality rate of $40 \%$ was reported by Ubesie et al. ${ }^{21}$ in Enugu, Nigeria. These observations attest to wide variations in the outcome of care for children with SAM and calls for more efforts by stakeholders at improving care for children with this condition.

The small sample size of this study is a major limitation as only few cases were found during the study period. However, our finding may be an attestation to the finding of earlier authors ${ }^{30}$ that some cases of SAM may be on a decline in the southwestern part of Nigeria. Additionally, there 
were challenges of incomplete and missing data due to the retrospective design of our study.

\section{CONCLUSIONS}

Many of the children admitted for SAM in our study had social problems and most of them left the hospital against medical advice because of some forms of social challenges which included financial constraints. Community based management of acute malnutrition programme will help address some of these challenges and improve outcome. Furthermore, the breast feeding practice of mothers of patients in this study was very poor and could have contributed to the development of SAM in their wards. Hence, more aggressive health education on breastfeeding and adoption of guidelines on breastfeeding of infants could help to lessen the burden of SAM in our locality. In addition, the observation that only cases of marasmus were associated with HIV as found in this study and one earlier report ${ }^{24}$ needs to be further researched to establish if truly there is no causal effect relationship between HIV and kwashiorkor.

\section{REFERENCES}

1. World Health Organization. Global Health Observatory (GHO) data. Child Malnutrition Available from: http://www.who.int. [Accessed 24th May, 2018].

2. Federal Ministry of Health (Nigeria). Health Sector component of National Food and Nutrition Policy: National Strategic plan of action for Nutrition (2014-2019). 2014. Abuja Nigeria: Federal Ministry of Health.

3. United Nations Children Fund. Uniting in the battle to end Child malnutrition in Nigeria. Available from: http://www.unicef.org. [ Accessed 25 May, 2018].

4. Population Reference Bureau (Nigeria). Malnutrition: Nigeria's silent crisis. Available from: https://assets.prb.org.[ Accessed 26 ${ }^{\text {th }}$ May, 2018]

5. United Nations Children Fund. Over a million children reached with life- saving malnutrition treatment. Available from: https://www.unicef.org. [Accessed 5 $5^{\text {th }}$ October, 2018]

6. Federal Ministry of Health (Nigeria). National Guidelines for inpatient management of Severe Acute Malnutrition in infants and young children in Nigeria. 2016. Abuja Nigeria: Federal Ministry of Health.

7. Wellcome Trust Working Party. Classification of infantile malnutrition. Lancet. 1970;2:302-3

8. Dhanalakshmi K., Gayathri Devi C. The outcome of severe acute malnutrition children admitted to Nutrition Rehabilitation Centre of a tertiary level care hospital. Int J Contemp Pediatr 2017;4:801-3. DOI: http://dx.doi.org/10.18203/2349-3291.ijcp20171490

9. Ali SM, Meshram HS. A hospital-based study of severe acute malnutrition in infants less than six months and comparison with severe acute malnutrition in children 6-60 months. Sri Lanka J. Child Health 2017; 46: 234-237. DOI: http://doi.org/10.4038/sljch.v46i3.8324

10. Walana W, Acquah SEK, Makinin S, Sarfo M, Muktar AB, Vicar EK, et al. A Retrospective Study on Child Malnutrition in the Tamale Teaching Hospital, Ghana. JSRR 2016;10:1-12. DOI: 10.9734/JSRR/2016/23095

11. Chiabi A, Malangue B, Nguefack S, Dongmo FN, Fru F, Takou V, et al. The clinical spectrum of severe acute malnutrition in children in Cameroon: a hospital-based study in Yaounde, Cameroon Trans1 Pediatr. 2017;6:32-39. DOI: 10.21037/tp.2016.07.05.

12. Badi MA, Ba-Saddik IA. Severe Acute Malnutrition among Hospitalised Children, Aden, Yemen Open J. Epidemiol. 2016;6:121-7. DOI: 10.4236/ojepi.2016.62012

13. Choudhary M, Sharma D, Nagar RP, Gupta BD, Nagar T, Pandita A. Clinical Profile of Severe Acute Malnutrition in Western Rajasthan: A Prospective Observational Study from India. J Pediatr Neonatal Care. 2015;2:00057. DOI: 10.15406/jpnc.2015.02.00057

14. Irena $\mathrm{AH}$, Mwambazi M, Mulenga V. Diarrhoea is a major killer of children with severe acute malnutrition admitted to inpatients set up in Lusaka, Zambia. Nutr J. 2011;10:110-5. DOI: 10.1186/1475-2891-10-110

15. Musa MK, Muhammad F, Lawal KM, Chowdhury ABMA, Hossain A. Risk Factors of Severe Acute Malnutrition among Under-five Children: A Hospital-based Study in Bangladesh. J Med Sci Health. 2017;3:13-21

16. Saka AO, Saka MJ, Ojuawo A, Abdulkarim AA, Bilamin SA, Latubosun L, et al. Haematological Profile in Children with Protein Energy Malnutrition in North Central Nigeria Glob. J. Med. Res. 2012;12: 9-14 
17. Das S, Paul DK, Bhattacharya M, Basu S, Chatterjee A, Sen S, et al. Clinicoepidemiological Profile, Risk Factors and Outcome of Severe Acute Malnutrition Children at the Nutritional Rehabilitation Centre of a Tertiary Care Centre in Eastern India- A 4 year experience. Adv Res Gastroentero Hepatol 2017;5:1-8. DOI:10.19080/ARGH.2017.05.555659

18. Baruah MN, Gogoi B, Biswanath P. Clinical Profile of Children with Severe acute Malnutrition Admitted to the Nutritional Rehabilitation Centre of a Tertiary Care Teaching Hospital of Assam. JMSCR 2018;06:944-8 DOI: https://dx.doi.org/10.18535/jmscr/v6i3.157

19. Rao S, Joshi SB, Kelkar RS. Change in nutritional status and morbidity over time in preschool children from slums in Pune, India. Indian Pediatr 2000;37:1060-71. PMID: 11042704.

20. Kabalo MY, Seifu CN. Treatment outcomes of severe acute malnutrition in children treated within Outpatient Therapeutic Program (OTP) at Wolaita Zone, Southern Ethiopia:retrospective cross-sectional study. J Health Popul and Nutr 2017;36:7. doi: 10.1186/s41043-017-0083-3.

21. Ubesie AC, Ibeziako NS, Ndiokwelu CI, Uzoka CM, Nwafor CA. Under-five protein energy malnutrition admitted at the University of Nigeria Teaching Hospital, Enugu: a 10 year retrospective review. Nutr J. 2012;11:43. DOI:https://doi.org/10.1186/1475-2891-11-43

22. Gabbad AA, Adam A, Elawad MA. Epidemiological aspects of malnutrition in children less than five years admitted to Gaafar Ibn oaf paediatric hospital, Khartoum, Soudan. AJSC. 2014;3:67-72.

23. Misganaw C, Mesfin M, Tesfaye M, Derese A. Retrospective study on outcome of in-patient of severe acute malnutrition in Jimma University Specialised Hospital from September 2011-September 2012. JOD. 2014;1:18-27. DOI: 10.18488/journal.98/2014.1.1/98.1.18.27

24. Adejuyigbe EA, Oyelami O, Onayemi O, Durosinmi MA. Paediatric HIV/AIDS in Ile-Ife, Nigeria. Cent Afr J Med. 2003;49:74-8.

25. Nhampossa T, Siquaque B, Machevo S, Macete E, Alonso P, Bassat Q, et al. Severe malnutrition among children under the age of 5 years admitted to a rural district hospital in southern Mozambique. Public Health Nutr. 2013;16:1565-74. DOI: 10.1017/S1368980013001080.

26. Burrell A, Kerac M, Nabwera H. Monitoring and discharging children being treated for severe acute malnutrition using mid-upper arm circumference. Secondary data analysis from rural Gambia. Int Health. 2017;9:226-233 DOI: 10.1093/inthealth/ihx022.

27. Ndzo JA, Jackson A. Outcomes of children aged 6-59 months with severe acute malnutrition at the GADO outpatient therapeutic center in Cameroon. BMC Res Notes. 2018;11:68. DOI: 10.1186/s13104-018-3177-0

28. Eze B, Agu K, Nwosu J. Discharge against medical advice at a tertiary centre in southeastern Nigeria: Sociodemographic and clinical dimensions. Patient Intell. 2010;2:27-31. DOI: 10.2147/PI.S11337

29. Fadare JO, Babatunde OA, Olanrewaju T, Busari O. Discharge against medical advice: Experience from a rural Nigerian hospital. Ann Nigerian Med. 2013;7:60-5. DOI: 10.4103/0331-3131.133098

30. Oyelami OA, Ogunlesi TA. Kwashiorkor- is it a dying disease. S Afr Med J. 2007;97:65-68. PMID: 17378286 